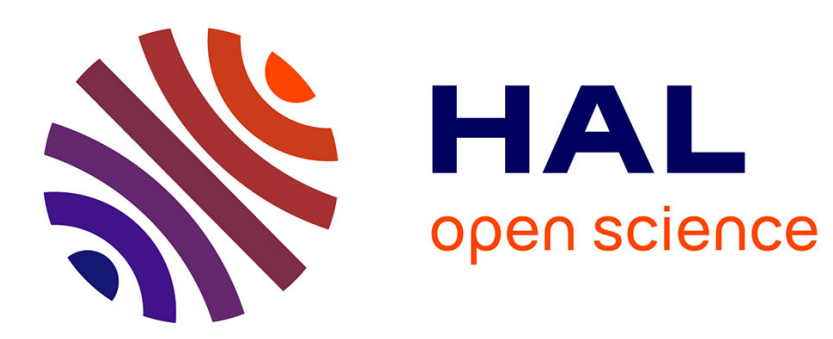

\title{
An Unknown Input HOSM Approach to Estimate Lean and Steering Motorcycle Dynamics
}

Lamri Nehaoua, Dalil Ichalal, Hichem Arioui, Jorge Davila, Saïd Mammar, Leonid Fridman

\section{- To cite this version:}

Lamri Nehaoua, Dalil Ichalal, Hichem Arioui, Jorge Davila, Saïd Mammar, et al.. An Unknown Input HOSM Approach to Estimate Lean and Steering Motorcycle Dynamics. IEEE Transactions on Vehicular Technology, 2014, 63 (7), pp.3116-3127. 10.1109/TVT.2014.2300633 . hal-00935371

\section{HAL Id: hal-00935371 \\ https://inria.hal.science/hal-00935371}

Submitted on 23 Jan 2014

HAL is a multi-disciplinary open access archive for the deposit and dissemination of scientific research documents, whether they are published or not. The documents may come from teaching and research institutions in France or abroad, or from public or private research centers.
L'archive ouverte pluridisciplinaire HAL, est destinée au dépôt et à la diffusion de documents scientifiques de niveau recherche, publiés ou non, émanant des établissements d'enseignement et de recherche français ou étrangers, des laboratoires publics ou privés. 


\title{
An Unknown Input HOSM Approach to Estimate Lean and Steering Motorcycle Dynamics
}

\author{
Lamri Nehaoua, Dalil Ichalal, Hichem Arioui, Jorge Davila, Said Mammar, and Leonid Fridman
}

\begin{abstract}
This paper deals with state estimation of Powered Single-Track vehicle and robust reconstruction of related unknown inputs. For this purpose, we consider an unknown input high order sliding mode observer (UIHOSMO). First, a motorcycle dynamic model is derived using Jourdain's principle. The strong observability of the obtained model is illustrated. Then, we consider both the observation of the PTW dynamic states and the reconstruction of the lean dynamics and the rider's torque applied on the handlebar. Finally, several simulation cases are provided to illustrate the efficiency of the observer.
\end{abstract}

Index Terms-Motorcycle, HOSM, Strong Observability.

\section{INTRODUCTION}

$\mathbf{R}$ Ecently, the use of powered single-track vehicles is constantly growing, upsetting driving practices and road traffic. Unfortunately, this expansion is also inflected by an important increase of motorcycle's fatalities (20 times higher when driving a car). Recent statistics confirm this observation and consider riders as the most vulnerable road users. In 2010, the French Agency of Road Safety made a finding of around 1000 deaths (25\% of traffic fatalities), while the traffic proportion of motorcycles does not exceed $1 \%$. Several research programs are launched to answer this issue and to find solutions in term of preventive and / or active security systems, [1], [2].

The success, of the proposed security systems, depends primarily on the knowledge of the dynamics of motorcycle and, the evolution of its states (to be observed) strongly involved by the rider's action (to be reconstructed) and/or the infrastructure features (slope, tilt, adherence, etc.). Regarding the first point, several studies were carried out in order to understand the motorcycle dynamics (see, for example [3][6]), the stability analysis of powered two-wheeled (PTW), optimal and safe trajectories [7], [8] and the proposal of risk functions (see [9], [10], [31]) to detect borderline cases of control loss. These research are very few sustainable if they are not propped by a system for estimating the dynamic states of the bike.

The real measurement, by sensors, of all the bike states is not conceivable. Thus, we propose to use observation techniques to overcome measurement noise, expensive sensors, etc. Within this context, including all methodologies, very few studies exist [11]-[13].

The first work on the state estimation for motorcycles date back to 2008 [14]. Researches sustain this topic have commonly concerned the estimation of the lean dynamics and considerably less the steering one. Several approaches have been experimented to estimate the roll angle: frequency separation filtering [16] or extended Kalman filters, [17]. These techniques, performed under restrictive assumptions (dynamic steering is neglected, linear tire-road forces, etc.), suffer mainly from a relative robustness against the variations of the forward velocity.

The issue of the steering angle estimation, and not the rider's torque reconstruction, is not well covered in literature as the lean angle estimation problem. Nonetheless, a recent results have been obtained in [18]-[21], where an LPV observer has been used to design control strategy for a semi-active steering. The approach is a simple gain scheduling for an LTI motorcycle model under three constant forward velocities. Unfortunately, no guarantees for stability or convergence of the proposed observer are given. In [22], [23], approaches based on Takagi-Sugeno fuzzy models are used in order to cover a large operating range of the system which allows to take into account some inherent nonlinearities in the motorcycle model. This aims to construct an observer able to estimate the states in several situations where the nonlinear dynamics are excited (cornering situation, saturated contact forces tireroad,...). These last works give a new direction for nonlinear observation and constitute primary results in this topic.

To the best authors' knowledge, the simultaneous estimation of the lean and the steering dynamics have never been addressed. The present work proposes a robust UIHOSMO [24], helping in states observation of motorcycle model and the reconstruction of rider's action under parameter uncertainties. Sliding-mode observer (SMO) for system states estimation in the presence or absence of unknown inputs has been the subject of several work. Nowadays, one can notice that observation theory has matured and has succeed to deal with many technical issues [25], [26] where some restrictive conditions related to the observability and the reconstruction of unknown inputs were released even suppressed.

To avoid filtering, the discontinuous output injection is replaced by a continuous super-twisting algorithm (STA) [28]. In this new version, the relative degree of the system's outputs with respect to the unknown inputs must be equal to the system order. This restriction is resolved by the introduction of the high-order Sliding-mode observers (HOSMO) [24], based on the high-order robust exact Sliding-mode differentiator [29], where the notion of strong observability and strong detectability were presented. It remains at least that the outputs relative degree must exist which brings a novel restriction treated by the development of the concept of weakly observable subspaces detailed in [30].

In this paper, we suggest to use HOSMO higher order sliding mode observers. Theoretically, the HOSMO provide finite 
time exact convergence for the system states and unknown inputs. Moreover, HOSMO ensure best possible accuracy with respect to sampling steps and bounded disturbances without need of a priori knowledge of the upper bound of disturbances and the size of the sampling step [27].

The paper contributions are the following:

- A motorcycle dynamic model is derived.

- It is a first paper (for the authors best knowledge) when the theory of strong observability/detectability are applied to the problem of reconstruction for motorcycles steering dynamics.

- To realize the reconstruction of the motorcycles states and unknown inputs, UIHOSM observers were chosen. Due to non-minimum phase nature of the motorcycle dynamics model, the direct estimation of the lean angle as a state variable is not possible. To overcome this problem, the model is rearranged in order to consider the lean angle as an unknown input to be reconstructed. The strong observability property is then used.

- Various results for modeling and observation are discussed and validated by using a high-end motorcycle software simulator.

This paper is organized as follows: sections [II and III are dedicated respectively to motorcycle modeling and the synthesis of the UIHOSMO. Simulation results are given is section [V] The conclusion in section $\nabla$ wrap up the paper.

\section{MOtORCYCLE DYNAMICS}

This section highlights some outlines for the PTW modeling. Firstly, the model to be used for the validation step (section V) is described . Next, for observer synthesis, a dedicated model is derived.

\section{A. Modeling Assumptions}

In figure 1, the considered geometrical configuration of the modeled vehicle is shown. The motorcycle is represented as a set of eight linked bodies: the main frame $G_{r}$ which includes the chassis and engine, the front body $G_{f}$ which represents the steering assembly, the lower body $G_{l}$ which includes the lower suspension part and the front wheel hub, the swing-arm body $G_{s}$, the front and rear wheel $R$, the upper and the lower parts of the rider body $G_{B}$. The rider is considered as to be solidly attached to the main body $G_{r}$ and, its posture stays in the upright plan of the motorcycle symmetry plan.

The motion of the overall mechanical system is expressed at point $v$, origin of the vehicle reference frame $\Re_{v}$. The equation of motion, developed by using Jourdain's principle of dynamics [33], allows to simulate 11 degrees of freedom (DoF): the velocity vector of point $v\left(v_{x}, v_{y}, v_{z}\right)$ the yaw, pitch and roll of the main frame $G_{r}(\psi, \theta, \varphi)$, the handlebar steer angle $\delta$ with respect to the rider torque input $\tau_{r}$ applied on the motorcycle's handlebar, swing-arm motion $\mu$ and the two wheels spin.

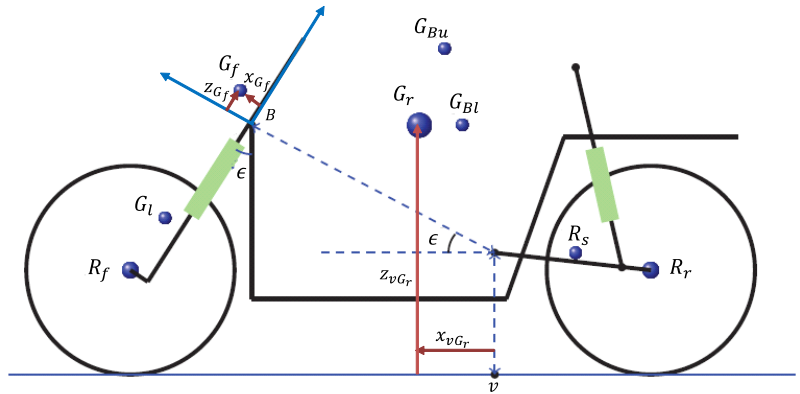

Fig. 1. Geometrical representation of the motorcycle vehicle

The dynamic model of the motorcycle vehicle can be expressed in a compact form by:

$$
\boldsymbol{M} \dot{\vartheta}=Q
$$

where the mass matrix $M$ is symmetric and positive definite and $Q$ is the vector of the generalized efforts.

\section{B. Linearized Model for Observer Synthesis}

The study of the dynamics of motorcycle vehicles highlights two main modes of motion: in-plane mode representing the motorcycle movements in its plane of symmetry including the longitudinal motion and that of suspensions and the outof-plane mode which describes the lateral dynamics when cornering [3], [32]. The last mode involves the roll inclination, the yaw rotation, the steering and the lateral motions of the bike. We consider here only the out-of-mode dynamics of the PTW. The coupling between the two modes is materialized, when necessary, by considering a variable longitudinal velocity that appears in the lateral dynamics.

The motorcycle dynamic model (1) is linearized around the straight-running trim trajectory and can be expressed by the following state-space:

$$
\begin{aligned}
\dot{\boldsymbol{x}}_{v} & =\boldsymbol{A}_{v} \boldsymbol{x}_{v}+\boldsymbol{B}_{v} \tau_{r} \\
\boldsymbol{y}_{v} & =\boldsymbol{C}_{v} \boldsymbol{x}_{v}
\end{aligned}
$$

here, $\boldsymbol{x}_{v}=\left[v_{y}, \dot{\psi}, \dot{\varphi}, \dot{\delta}, \varphi, \delta, F_{y f}, F_{y r}\right]^{T}$ denotes the state vector. $F_{y f}$ and $F_{y r}$ represent respectively the tires sideslip forces introduced in the state space representing the tire relaxation. $\boldsymbol{A}_{v}$ is a time-varying matrix related to the forward velocity $v_{x}$ while $\boldsymbol{B}_{v}$ is a time-invariant vector where $\boldsymbol{A}_{v}=\Lambda^{-1} \boldsymbol{E}$ and, $\boldsymbol{B}_{v}=\Lambda^{-1}[0,0,0,1,0,0,0]^{T}$. Matrices $\Lambda$ and $\boldsymbol{E}$ are given appendix.

\section{STATES AND UNKNOWN INPUTS Estimation}

In this section, we aim to estimate the motorcycle states and reconstruct both roll angle $\varphi$ and rider's torque $\tau_{r}$ by using a UIHOSMO [24].

In our case, we consider that the measured variables are the steering angle by means of a digital encoder sensor and, angular velocities by using inertial unit where the forward velocity can be also deduced. Sensor measurement noises and effect vibration will be considered to be matched disturbance. 
At first, we recall some important definitions about strong observability and strong detectability of linear systems (for proofs see [34], [24]).

Consider the following SISO system, where $x \in \mathbb{R}^{n}, \zeta \in \mathbb{R}$ is the unknown input and $y \in \mathbb{R}$ is the measured output:

$$
\begin{aligned}
\dot{\boldsymbol{x}} & =\boldsymbol{A} \boldsymbol{x}+\boldsymbol{B} u+\boldsymbol{D} \zeta \\
y & =\boldsymbol{C} \boldsymbol{x}
\end{aligned}
$$

Definition 3.1: ([34]). $s_{0} \in \mathbb{C}$ is called an invariant zero of the triplet $(\boldsymbol{A}, \boldsymbol{D}, \boldsymbol{C})$ if $\operatorname{rank}\left\{\boldsymbol{R}\left(s_{0}\right)\right\}<n+\operatorname{rank}\{\boldsymbol{D}\}$, where $\boldsymbol{R}(s)$ is the Rosenbrock matrix of system (4):

$$
\boldsymbol{R}(s)=\left[\begin{array}{cc}
s \boldsymbol{I}-\boldsymbol{A} & -\boldsymbol{D} \\
\boldsymbol{C} & \mathbf{0}
\end{array}\right]
$$

Let us recall ( [35]) that the relative degree of the output $y$ with respect to the unknown input $\zeta$ is the scalar $r$ such that:

$$
\begin{aligned}
& \boldsymbol{C} \boldsymbol{A}^{j} \boldsymbol{D}=0 \quad j=1, \cdots, r-2, \\
& \boldsymbol{C} \boldsymbol{A}^{r-1} \boldsymbol{D} \neq 0 .
\end{aligned}
$$

Definition 3.2: ([34]). System (4) is called strongly observable if for any initial state $x(0)$ and any unknown input $\zeta(t)$ ), $y(t) \equiv 0$ for all $t \geq 0$ implies that also $x \equiv 0$. Otherwise, (4) is called strongly detectable, if for any $\zeta(t)$ and $x(0), y(t)=0$ for all $t \geq 0$ implies that $x \rightarrow 0$ as $t \rightarrow \infty$.

Proposition 3.1: ( [34], [24]). The following statements are equivalent:

1) The system (4) is strongly observable.

2) The triplet $(\boldsymbol{A}, \boldsymbol{D}, \boldsymbol{C})$ has no invariant zeros.

3) The output $y$ of system (4) has relative degree $r=n$ with respect to the unknown input $\zeta$.

Otherwise, the following statements are also equivalent:

1) The system (4) is strongly detectable,

2) The relative degree $r$ of the system's output $y$ with respect to the unknown input $\zeta$ exists, and the triplet $(\boldsymbol{A}, \boldsymbol{D}, \boldsymbol{C})$ has a stable invariant zeros (system (4) is minimum phase).

For the MIMO system case, the strong observability and detectability can be reformulated by reconsidering the definition of the relative degree. For this, let be the system (4), where $\boldsymbol{x} \in \mathbb{R}^{n}, \boldsymbol{y} \in \mathbb{R}^{m}$ is the output vector and $\boldsymbol{\zeta} \in \mathbb{R}^{m}$ is the unknown input vector.

The output $\boldsymbol{y}$ is said to have the vector relative degree $\boldsymbol{r}=$ $\left[r_{1}, \cdots, r_{m}\right]$ with respect to the unknown input $\boldsymbol{\zeta}([34])$, if

$$
\begin{aligned}
& \boldsymbol{C}_{i} \boldsymbol{A}^{s} \boldsymbol{D}_{j}=0 \quad i, j=1, \cdots, m, \quad s=1, \cdots, r_{i}-2 \\
& \boldsymbol{C}_{i} \boldsymbol{A}^{r_{i}-1} \boldsymbol{D}_{j} \neq 0
\end{aligned}
$$

and

$$
\operatorname{det}\left[\begin{array}{ccc}
\boldsymbol{C}_{1} \boldsymbol{A}^{r_{1}-1} \boldsymbol{D}_{1} & \cdots & \boldsymbol{C}_{1} \boldsymbol{A}^{r_{1}-1} \boldsymbol{D}_{m} \\
\vdots & \vdots & \vdots \\
\boldsymbol{C}_{m} \boldsymbol{A}^{r_{m}-1} \boldsymbol{D}_{1} & \cdots & \boldsymbol{C}_{m} \boldsymbol{A}^{r_{m}-1} \boldsymbol{D}_{m}
\end{array}\right] \neq 0
$$

Lemma 3.1: ( [24]). Let the output $\boldsymbol{y}$ of (4) have the vector relative degree $\boldsymbol{r}=\left[r_{1}, \cdots, r_{m}\right]$ with respect to the unknown input $\boldsymbol{\zeta}$. Then the vectors $\boldsymbol{C}_{1}, \ldots, \boldsymbol{C}_{1} \boldsymbol{A}^{r_{1}-1}, \ldots, \boldsymbol{C}_{m}, \ldots$, $\boldsymbol{C}_{m} \boldsymbol{A}^{r_{m}-1}$ are linearly independent.

\section{A. Case 1: estimation of the roll angle}

The motorcycle dynamics system (2) has $n=8$ states, one output which corresponds to the steering angle $\delta$, measured by a digital encoder sensor, and one unknown input corresponding to the rider's torque $\tau_{r}$ applied on the motorcycle handlebar. From definition (3.1), the triplet $\left(\boldsymbol{A}_{v}, \boldsymbol{D}_{v}, \boldsymbol{C}_{v}\right)$ has one unstable invariant zero which makes the motorcycle dynamics to be a non-minimum phase. In addition, the system's output has relative degree $r=2<n$ with respect to the unknown input $\zeta$. It follows from proposition (3.1) that the motorcycle dynamics system (2) is neither observable nor detectable, and thus for all $v_{x}$ in the allowable velocities range.

In order to make the system observable, the motorcycle model (2) is rewritten in such way that the roll angle $\varphi$ appears as an unknown input rather than a state variable. In fact, the unstable invariant zero is a direct consequence of the countersteering phenomena generated by the motorcycle roll. In this case, the new system equation are:

$$
\begin{aligned}
\dot{\boldsymbol{x}}_{p} & =\boldsymbol{A}_{p} \boldsymbol{x}_{p}+\boldsymbol{B}_{p} \tau_{r}+\boldsymbol{D}_{p} \varphi \\
y_{p} & =\delta=\boldsymbol{C}_{p} \boldsymbol{x}_{p}
\end{aligned}
$$

where $\boldsymbol{x}_{p}=\left[v_{y}, \dot{\psi}, \dot{\varphi}, \dot{\delta}, \delta, F_{y f}, F_{y r}\right]^{T}$ denotes the state vector.

The output $y_{p}$ of system (5) has a relative degree $r=2$ with respect to the unknown input $\varphi$. In addition, the triplet $\left(\boldsymbol{A}_{p}, \boldsymbol{D}_{p}, \boldsymbol{C}_{p}\right)$ has 5 stable invariant zeros for all $v_{x}$ in the allowable velocities range. It results from proposition (3.1), that (5) is strongly detectable. This definition implies that only $r$ system's states can be estimated exactly while the observation of the remaining states are asymptotically exact.

To estimate the system's state vector $\boldsymbol{x}_{p}$ and the unknown input $\varphi$, it is necessary to separate the clean states from those contaminated by the unknown input. To achieve this, system (5) is transformed to a new coordinates system $\boldsymbol{\xi}_{p}=\boldsymbol{T} \boldsymbol{x}_{p}$ such that the closed-loop system dynamics $\left(\boldsymbol{A}_{p}-\boldsymbol{C}_{p} \boldsymbol{L}_{p}, \boldsymbol{D}_{p}, \boldsymbol{C}_{p}\right)$ is expressed by:

$$
\begin{aligned}
& \dot{\xi}_{11}=\xi_{12}+b_{11} \tau_{r} \\
& \dot{\xi}_{12}=a_{1} \xi_{11}+a_{2} \xi_{12}+a_{3} \xi_{21}+\cdots+a_{7} \xi_{25}+b_{12} \tau_{r}+d_{\varphi} \varphi \\
& \dot{\xi}_{2}=\boldsymbol{A}_{21} \boldsymbol{\xi}_{1}+\boldsymbol{A}_{22} \boldsymbol{\xi}_{2}+\boldsymbol{B}_{2} \tau_{r} \\
& y_{p, \text { new }}=\xi_{11},
\end{aligned}
$$

where $\boldsymbol{\xi}_{p}^{T}=\left[\boldsymbol{\xi}_{1}^{T}, \boldsymbol{\xi}_{2}^{T}\right] \in \mathbb{R}^{n}$ and $\boldsymbol{\xi}_{1}^{T}=\left[\xi_{11}, \xi_{12}\right] \in \mathbb{R}^{r}$ and $\boldsymbol{\xi}_{2}^{T}=\left[\xi_{21}, \cdots, \xi_{25}\right] \in \mathbb{R}^{n-r}$. Since the system is strongly detectable, the observer gain $\boldsymbol{L}_{p}$ can be chosen such that $\left(\boldsymbol{A}_{p}-\right.$ $\left.\boldsymbol{L}_{p} \boldsymbol{C}_{p}\right)$ is Hurwitz. It follows that the state observer have the form: 


$$
\begin{aligned}
& \dot{\boldsymbol{z}}_{p}=\boldsymbol{A}_{p} \boldsymbol{z}+\boldsymbol{B}_{p} \tau_{r}+\boldsymbol{L}_{p}\left(y_{p}-\boldsymbol{C}_{p} \boldsymbol{z}\right) \\
& \dot{\boldsymbol{\vartheta}}_{2}=\boldsymbol{A}_{21} \boldsymbol{\vartheta}_{1}+\boldsymbol{A}_{22} \boldsymbol{\vartheta}_{2} \\
& \hat{\boldsymbol{x}}_{p}=\boldsymbol{z}+\boldsymbol{T}^{-1} \boldsymbol{\vartheta},
\end{aligned}
$$

in which $\hat{\boldsymbol{x}}_{p}$ is the vector of the estimated states, $\boldsymbol{z} \in \mathbb{R}^{n}$ and $\vartheta \in \mathbb{R}^{n}$ is given by (recall that $n=7$ and $r=2$ ):

$$
\boldsymbol{\vartheta}=\left[\begin{array}{l}
\boldsymbol{\vartheta}_{1} \\
\boldsymbol{\vartheta}_{2}
\end{array}\right] \begin{aligned}
& \downarrow \mathbb{R}^{r} \\
& \downarrow \mathbb{R}^{n-r}
\end{aligned}=\left[\begin{array}{l}
v_{1} \\
v_{2} \\
\hline \boldsymbol{\vartheta}_{2}
\end{array}\right]
$$

in this equation, vector $\boldsymbol{\vartheta}$ components are composed from the observer's nonlinear injection $\boldsymbol{v} \in \mathbb{R}^{r+k+1}$. As reported in [24], since the unknown input $\varphi$ is bounded with an upper bound $|\varphi| \leq \varphi_{\max }$ and the $k$ successive derivatives of $\varphi$ are bounded by the same constant $\varphi_{\max }^{\prime}$, then by selecting a sufficiently large $\lambda, \boldsymbol{v}$ can be obtained by using a $(r+k)$-th order differentiator as following (for $k=1$ ):

$$
\begin{aligned}
& \dot{v}_{1}=-3 \lambda^{\frac{1}{4}}\left|v_{1}-y_{p}+\boldsymbol{C}_{p} \mathbf{z}\right|^{\frac{3}{4}} \operatorname{sign}\left(v_{1}-y_{p}+\boldsymbol{C}_{p} \mathbf{z}\right)+v_{2} \\
& \dot{v}_{2}=-2 \lambda^{\frac{1}{3}}\left|v_{2}-\dot{v}_{1}\right|^{\frac{2}{3}} \operatorname{sign}\left(v_{2}-\dot{v}_{1}\right)+v_{3} \\
& \dot{v}_{3}=-1.5 \lambda^{\frac{1}{2}}\left|v_{3}-\dot{v}_{2}\right|^{\frac{1}{2}} \operatorname{sign}\left(v_{3}-\dot{v}_{2}\right)+v_{4} \\
& \dot{v}_{4}=-1.1 \lambda \operatorname{sign}\left(v_{4}-\dot{v}_{3}\right)
\end{aligned}
$$

In addition, the reconstruction of the unknown input is possible by using:

$$
\hat{\varphi}=\frac{1}{d_{\varphi}}\left(v_{4}-a_{1} v_{1}-a_{2} v_{2}-a_{3} \vartheta_{2_{1}}-\cdots-a_{7} \vartheta_{27}-b_{12} \tau_{r}\right)
$$

\section{B. Estimation of the Roll Angle and Rider's Torque}

In this case study, the system equations are given by:

$$
\begin{aligned}
\dot{\boldsymbol{x}}_{p} & =\boldsymbol{A}_{p} \boldsymbol{x}_{p}+\boldsymbol{D}_{p p} \boldsymbol{\zeta}, \\
\boldsymbol{y}_{p p} & =\left[\begin{array}{c}
\delta \\
\dot{\psi}
\end{array}\right]=\boldsymbol{C}_{p p} \boldsymbol{x}_{p}, \\
\boldsymbol{D}_{p p} & =\left[\begin{array}{ll}
\boldsymbol{D}_{p} & \boldsymbol{B}_{p}
\end{array}\right], \quad \boldsymbol{\zeta}^{T}=\left[\begin{array}{ll}
\varphi & \tau_{r}
\end{array}\right] .
\end{aligned}
$$

From definition (3.1), the output $\boldsymbol{y}_{p p}$ in (10) has a relative degree vector $\boldsymbol{r}=[2,1]$ with respect to the unknown input vector $\boldsymbol{\zeta}$. In addition, the triplet $\left(\boldsymbol{A}_{p}, \boldsymbol{D}_{p p}, \boldsymbol{C}_{p p}\right)$ has 4 stable invariant zeros for all $v_{x}$ in the allowable velocities range. It results from Lemma (3.1), that (10) is also strongly detectable. This definition implies that only $r_{T}=r_{1}+r_{2}$ system's states can be estimated exactly while the observation of the remaining states are asymptotically exact.

As before, to estimate the system's state $\boldsymbol{x}_{p}$ and the unknown input vector $\zeta$, it is necessary to separate the clean states from those contaminated by the unknown inputs. To achieve this, system (10) is transformed to a new coordinates system $\boldsymbol{\xi}_{p}=\boldsymbol{T} \boldsymbol{x}_{p}$ such that the closed-loop system dynamics $\left(\boldsymbol{A}_{p}-\boldsymbol{C}_{p p} \boldsymbol{L}_{p p}, \boldsymbol{D}_{p p}, \boldsymbol{C}_{p p}\right)$ is expressed by:

$$
\begin{aligned}
& \dot{\xi}_{11}=\xi_{12}, \\
& \dot{\xi}_{12}=a_{11,11} \xi_{11}+a_{11,12} \xi_{12}+a_{11,13} \xi_{13}+a_{12,11} \xi_{21}+ \\
& \quad \cdots+a_{12,14} \xi_{24}+d_{11} \varphi+d_{12} \tau_{r}, \\
& \dot{\xi}_{13}=a_{11,21} \xi_{11}+a_{11,22} \xi_{12}+a_{11,23} \xi_{13}+a_{12,21} \xi_{21}+ \\
& \quad \cdots+a_{12,24} \xi_{24}+d_{21} \varphi+d_{22} \tau_{r}, \\
& \dot{\boldsymbol{\xi}}_{2}=\boldsymbol{A}_{21} \boldsymbol{\xi}_{1}+\boldsymbol{A}_{22} \boldsymbol{\xi}_{2}, \\
& \boldsymbol{y}_{\text {pp,new }}^{T}=\left[\begin{array}{ll}
\xi_{11} & \xi_{13}
\end{array}\right],
\end{aligned}
$$

where $\boldsymbol{\xi}_{p}^{T}=\left[\boldsymbol{\xi}_{1}^{T}, \boldsymbol{\xi}_{2}^{T}\right] \in \mathbb{R}^{n}$ and $\boldsymbol{\xi}_{1}^{T}=\left[\xi_{11}, \xi_{12}, \xi_{12}\right] \in \mathbb{R}^{r_{T}}$ and $\boldsymbol{\xi}_{2}^{T}=\left[\xi_{21}, \cdots, \xi_{24}\right] \in \mathbb{R}^{n-r_{T}}$. Next, the state observer is designed as:

$$
\begin{aligned}
& \dot{\boldsymbol{z}}=\boldsymbol{A}_{p} \boldsymbol{z}+\boldsymbol{L}_{p p}\left(\boldsymbol{y}_{p p}-\boldsymbol{C}_{p p} \boldsymbol{z}\right) \\
& \dot{\boldsymbol{\vartheta}}_{2}=\boldsymbol{A}_{21} \boldsymbol{\vartheta}_{1}+\boldsymbol{A}_{22} \boldsymbol{\vartheta}_{2} \\
& \hat{\boldsymbol{x}}_{p}=\boldsymbol{z}+\boldsymbol{T}^{-1} \boldsymbol{\vartheta}
\end{aligned}
$$

in which $\hat{\boldsymbol{x}}_{p}$ is the vector of estimated states, $\boldsymbol{z} \in \mathbb{R}^{n}$ and $\boldsymbol{\vartheta} \in \mathbb{R}^{n}$ is given by (recall that $n=7, r=[2,1]$ and $r_{T}=3$ ):

$$
\boldsymbol{\vartheta}=\left[\begin{array}{l}
\boldsymbol{\vartheta}_{1} \\
\boldsymbol{\vartheta}_{2}
\end{array}\right] \begin{aligned}
& \uparrow \mathbb{R}^{r_{T}} \\
& \uparrow \mathbb{R}^{n-r_{T}}
\end{aligned}=\left[\begin{array}{c}
v_{1,1} \\
v_{1,2} \\
v_{2,1} \\
\hline \boldsymbol{\vartheta}_{2}
\end{array}\right]
$$

Once again, $\boldsymbol{v}_{i} \in \mathbb{R}^{r_{M}+k+1}$ is the nonlinear part of the observer where $i=1, \cdots, m$ and $r_{M}=\max \left(r_{i}\right)$. Each unknown input $\zeta_{i}$ is bounded with $\left|\zeta_{i}\right| \leq \zeta_{i, \max }$ and the $\left(r_{M}-r_{i}+k\right)$ successive derivatives of $\zeta_{i}$ are bounded by the same constant $\zeta_{i, \max }^{\prime}$, consequently the auxiliary variable $\boldsymbol{v}_{i}$ is a solution of the discontinuous vector differential equation by considering $k=1$ as:

$$
\begin{aligned}
\dot{v}_{1,1} & =-3 \lambda^{\frac{1}{4}}\left|v_{1,1}-y_{p_{1}}+\boldsymbol{C}_{p_{1}} \boldsymbol{z}\right|^{\frac{3}{4}} \operatorname{sign}\left(v_{1,1}-y_{p_{1}}+\boldsymbol{C}_{p_{1}} \boldsymbol{z}\right) \\
& +v_{1,2} \\
\dot{v}_{1,2} & =-2 \lambda^{\frac{1}{3}}\left|v_{1,2}-\dot{v}_{1,1}\right|^{\frac{2}{3}} \operatorname{sign}\left(v_{1,2}-\dot{v}_{1,1}\right)+v_{1,3} \\
\dot{v}_{1,3} & =-1.5 \lambda^{\frac{1}{2}}\left|v_{1,3}-\dot{v}_{1,2}\right|^{\frac{1}{2}} \operatorname{sign}\left(v_{1,3}-\dot{v}_{1,2}\right)+v_{1,4} \\
\dot{v}_{1,4} & =-1.1 \lambda \operatorname{sign}\left(v_{1,4}-\dot{v}_{1,3}\right) \\
\dot{v}_{2,1} & =-2 \lambda^{\frac{1}{3}}\left|v_{2,1}-y_{p_{2}}+\boldsymbol{C}_{p_{2}} \boldsymbol{z}\right|^{\frac{2}{3}} \operatorname{sign}\left(v_{2,1}-y_{p_{2}}+\boldsymbol{C}_{p_{2}} \boldsymbol{z}\right) \\
& +v_{2,2} \\
\dot{v}_{2,2} & =-1.5 \lambda^{\frac{1}{2}}\left|v_{2,2}-\dot{v}_{2,1}\right|^{\frac{1}{2}} \operatorname{sign}\left(v_{2,2}-\dot{v}_{2,1}\right)+v_{2,3} \\
\dot{v}_{2,3} & =-1.1 \lambda \operatorname{sign}\left(v_{2,3}-\dot{v}_{2,2}\right)
\end{aligned}
$$

Finally, the reconstruction of the unknown input vector is possible by using:

$$
\begin{aligned}
& {\left[\begin{array}{c}
\hat{\varphi} \\
\hat{\tau}_{r}
\end{array}\right]=\overline{\boldsymbol{D}}^{-1}\left(\left[\begin{array}{c}
v_{1,3} \\
v_{2,2}
\end{array}\right]-\left[\begin{array}{lll}
a_{11,11} & \cdots & a_{12,14} \\
a_{11,21} & \cdots & a_{12,24}
\end{array}\right] \vartheta\right)} \\
& \overline{\boldsymbol{D}}=\left[\begin{array}{ll}
d_{11} & d_{12} \\
d_{21} & d_{22}
\end{array}\right]
\end{aligned}
$$


Remark 3.1: In the full relative degree case, all system's states can be exactly estimated and the observability matrix

$$
\boldsymbol{P}=\left[\begin{array}{c}
\boldsymbol{C}_{1} \\
\vdots \\
\boldsymbol{C}_{1} \boldsymbol{A}^{n-1} \\
\vdots \\
\boldsymbol{C}_{m} \\
\vdots \\
\boldsymbol{C}_{m} \boldsymbol{A}^{n-1}
\end{array}\right]
$$

can be chosen for the coordinates transformation $(\boldsymbol{T}=\boldsymbol{P})$. However, in the strongly detectable case, only $n-n_{u}$ system's states are exactly estimated where $n_{u}$ is the number of invariant zeros (see [30] for a deeper study of the problem). A possible choice of the transformation matrix $\boldsymbol{T}$ can be found in [36].

\section{VALIDATION RESULTS}

We recall here that the aim of our work is to address the states and unknown inputs estimation in order to derive efficient warning systems for riders. The context concerns mainly the urban situations (the linear and nonlinear dynamics are almost identical) and less sport motorcycles which are characterized by a strong nonlinear dynamics. This issue will be addressed in future.

In order to proof the efficiency of the proposed observer for motorcycle application, we shall respect the following steps:

- A comparison of our nonlinear model with one of the models using in BikeSim simulator. The comparison is achieved under two different scenarios. A discussion is given to highlights the differences between the two models.

- The second step concerns the linearization of our proposed nonlinear model around trim trajectories.

- Based on the linear model, a high order sliding mode observer is synthesized. To overcome the neglected nonlinearities, a robustness study is carried-out with respect to the forward speed time variations and parameter uncertainties.

- Finally, the HOSM observer is applied to the nonlinear model to estimates the roll $(\varphi)$ and the steering dynamics $\left(\tau_{r}\right)$.

\section{A. Assessment with BikeSim Simulator}

Despite some differences, both models shows a close behavior (by considering the same motorcycle parameters and degrees of freedom). Differences can be explained by the considered modeling assumptions summarized in the following point:

- The lateral velocities of both models are not identical. In our model, the lateral speed is expressed at point $v$ (figure 1), whereas, in BikeSim simulator, the same speed is calculated at the main frame center of gravity.
- In our modeling approach, the aerodynamic effort and flexibilities of the steering mechanics are neglected. In addition, the tire/road contact point is considered to be static and do not move throughout the tire circumference.

Figure 2 shows the result of a first scenario consisting of double lane change maneuver with longitudinal velocity of 100 $\mathrm{km} / \mathrm{h}$. Besides lateral velocities, all the other states are very close. The small differences are due to the precedent hypothesis assumed before. For example, the chattering phenomena we can observe on the steering dynamics is due to the lack of the flexibilities in our model. The same scenario is performed for $50 \mathrm{~km} / \mathrm{h}$ (figure 3 ) for which the previous remarks also hold.

A second scenario consists of a cornering maneuver with a constant radius maneuver with time varying forward speed in the interval $[50,100] \mathrm{km} / \mathrm{h}$ (figure 4). The both behaviors are similar. Nevertheless, a small difference of $0.2^{\circ}$ appears between the two steering angles. This is due, mainly, to the fact that the BikeSim simulator aims to compensates the aerodynamic effort, which is not the case of our model.

\section{B. Model linearization}

In order to synthesize the HOSM observer, the proposed nonlinear model is linearized with respect to the trim trajectories (roll angle close to zero). The dynamic behavior and tire road dynamics are linearized separately. The previous scenarios are simulated and presented below.

The double lane change scenario, under two different velocities (50 and $100 \mathrm{KhM}$ ), is presented on figures 5 and 6 We can notice that the behavior of the two cases are similar. This is mainly due to the constant velocity characteristics.

This is not obvious with the second scenario (constant radius with acceleration), where the differences are clear. Of course, this scenario is far from our addressed context and urban situation. The both models, under constant acceleration, do not fit at all (figure 7), because, among other reasons, of the huge camber angle and tire forces (point contact hypothesis).

\section{Observer design}

In this section, the UIHOSMO is constructed for the presented motorcycle model. Some results and discussions are provided to illustrate the effectiveness and the ability of the UIHOSMO in estimating simultaneously the dynamic states and both roll angle and the applied torque by the rider on the handlebar. The observer is designed in such a way to estimate all the dynamic states and unknown inputs from only the knowledge of steering angle $\delta(t)$ and the yaw rate $\dot{\psi}(t)$. The parameters $\lambda_{i}, i=1,2$ of the differentiator, in equations 13 and 14, are chosen as following: $\lambda_{1}=\lambda_{2}=5000$. The Luenberger gain $\boldsymbol{L}_{p p}$ in equation 12 is computed by pole placement at the eigenvalues: $-15,-30,-45,-60$, $-150,-165,-180$. With these parameters, the UIHOSMO is implemented with initial conditions $\hat{x}(0)=\left[\begin{array}{ll}0.1745 & 0.1745-\end{array}\right.$ $0.3491-0.0873 \quad 0.349150 \quad 50]$. Finally, validations are carried-out by using the nonlinear model. 

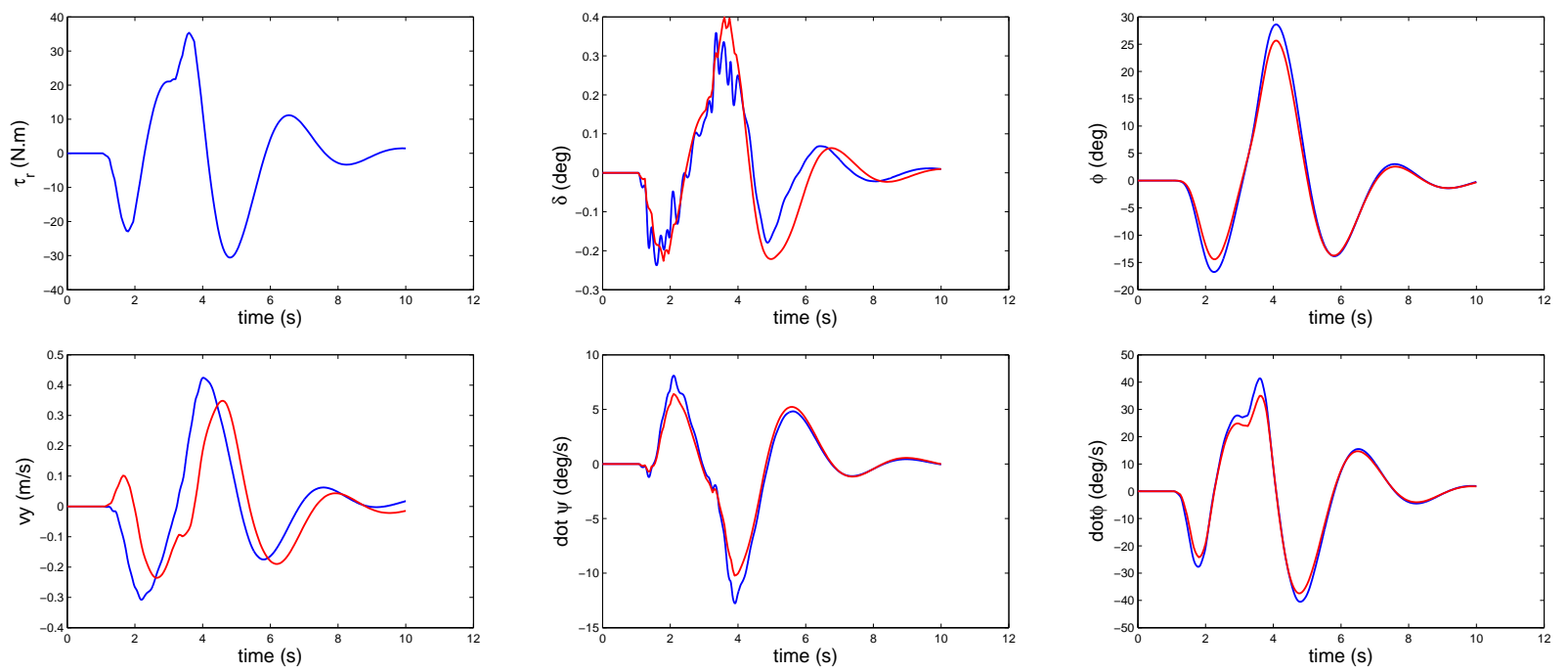

Fig. 2. Double lane change at $100 \mathrm{~km} / \mathrm{h}$. In blue, simulation of the nonlinear model and in red, simulation of Bikesim
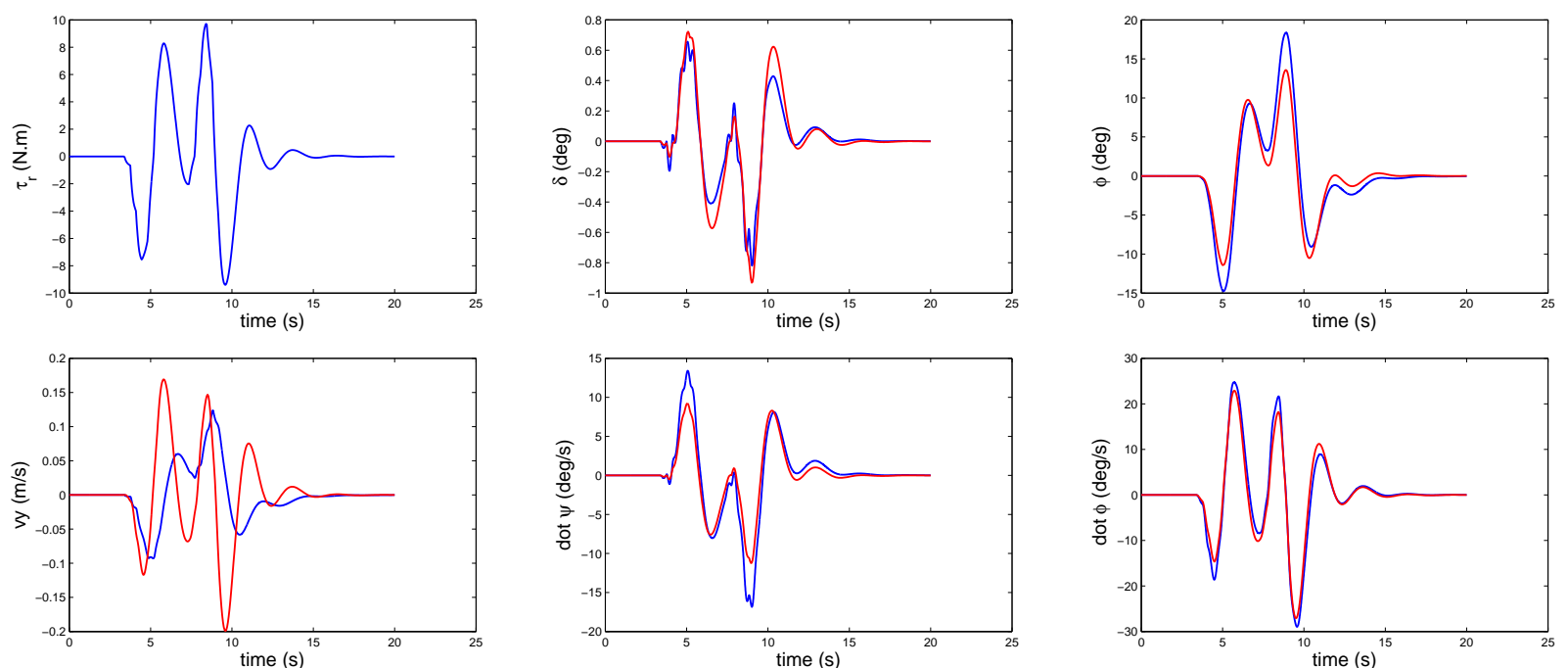

Fig. 3. Double lane change at $50 \mathrm{~km} / \mathrm{h}$. In blue, simulation of the nonlinear model and in red, simulation of Bikesim
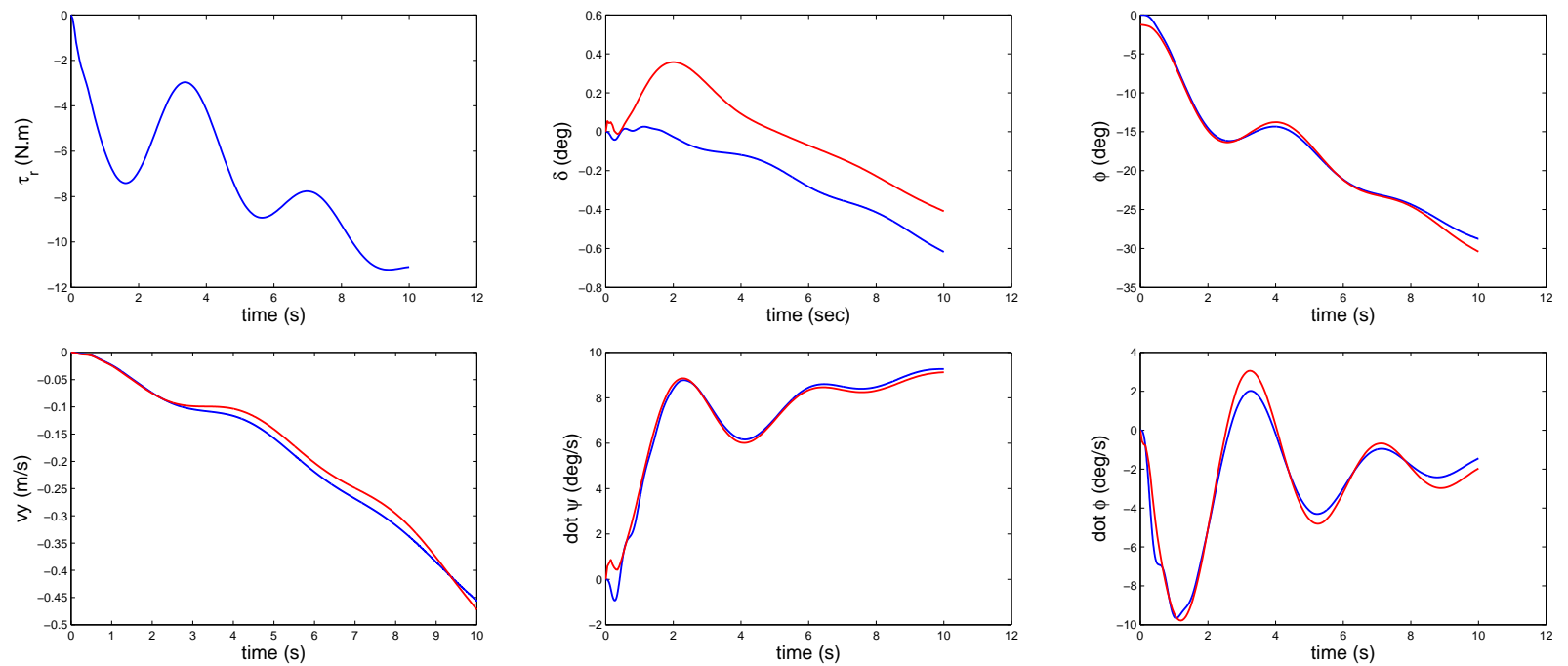

Fig. 4. Constant radius with acceleration from $50 \mathrm{~km} / \mathrm{h}$ to $100 \mathrm{~km} / \mathrm{h}$. In blue, simulation of the nonlinear model and in red, simulation of Bikesim 



Fig. 5. Double lane change at $100 \mathrm{~km} / \mathrm{h}$. In blue, simulation of the linear model and in red, simulation of nonlinear model
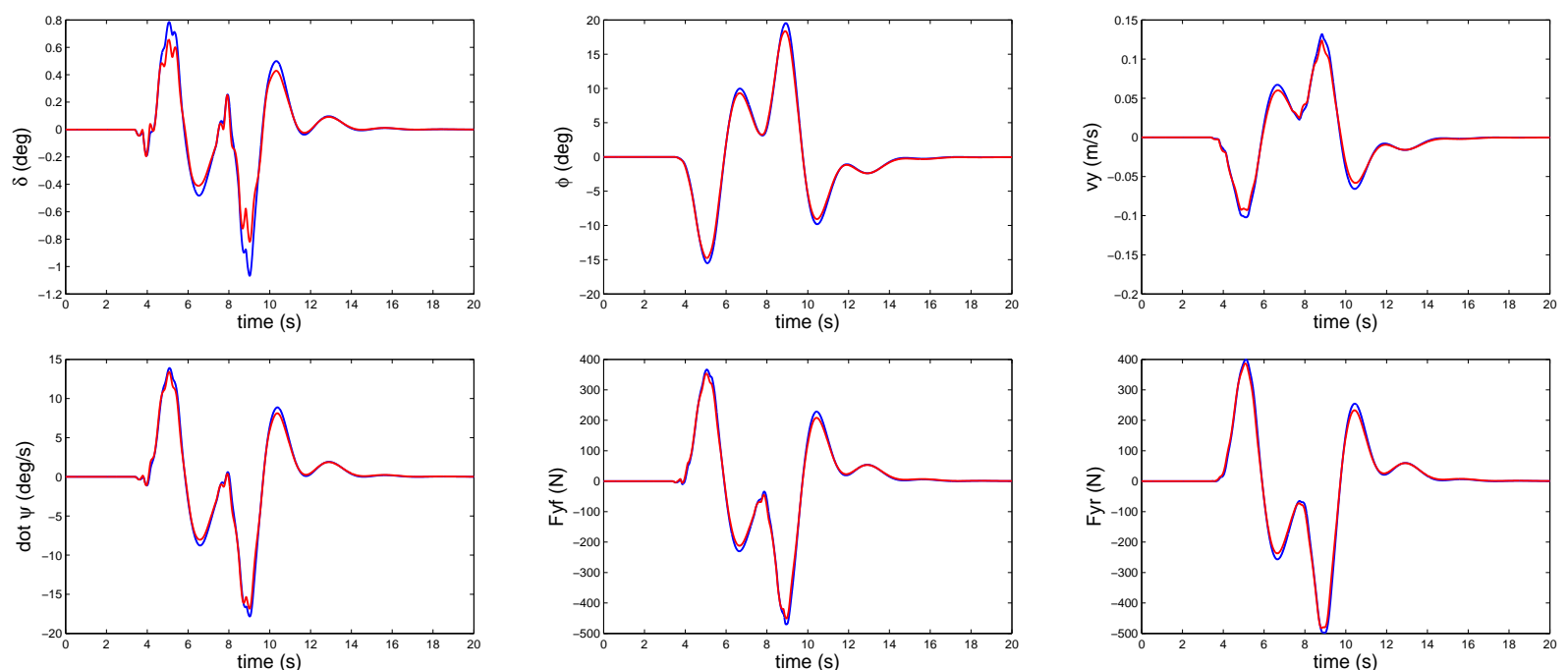

Fig. 6. Double lane change at $50 \mathrm{~km} / \mathrm{h}$. In blue, simulation of the linear model and in red, simulation of nonlinear model
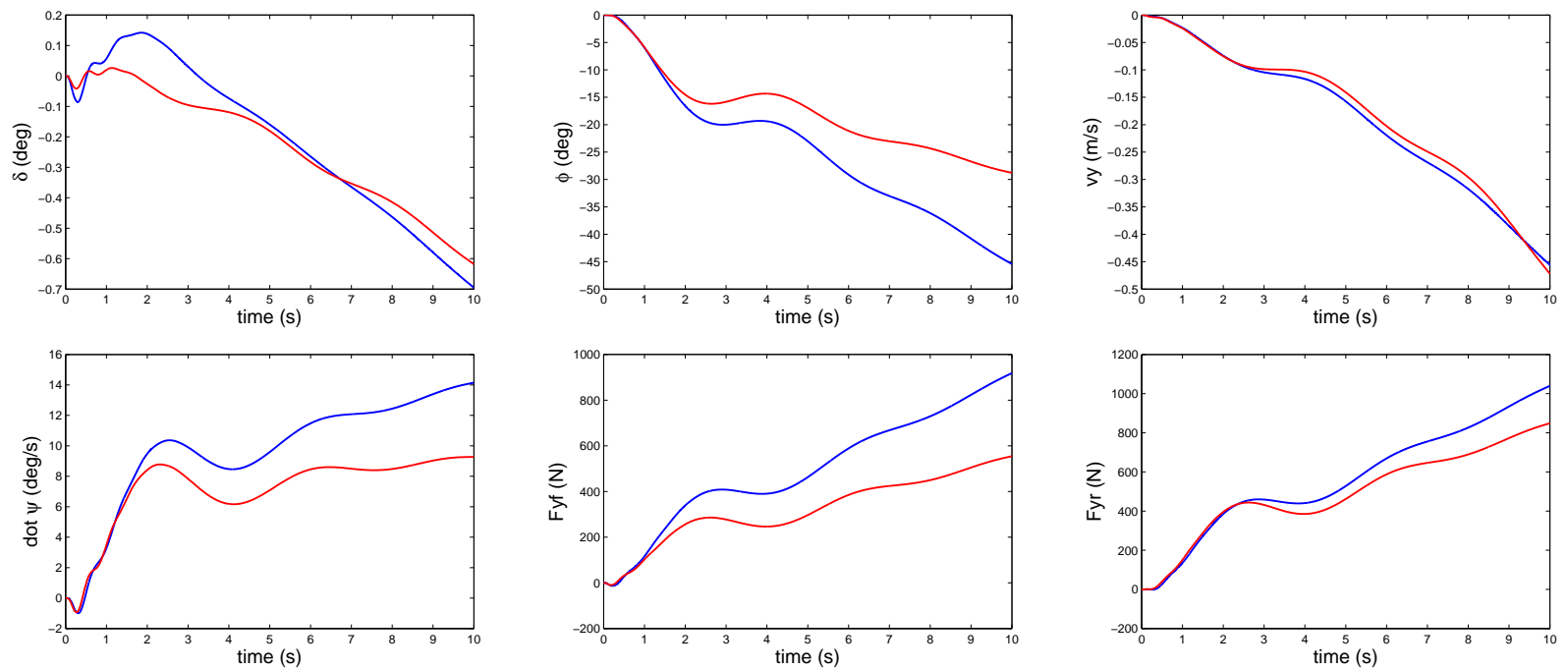

Fig. 7. Constant radius with acceleration from $50 \mathrm{~km} / \mathrm{h}$ to $100 \mathrm{~km} / \mathrm{h}$. In blue, simulation of the linear model and in red, simulation of nonlinear model 

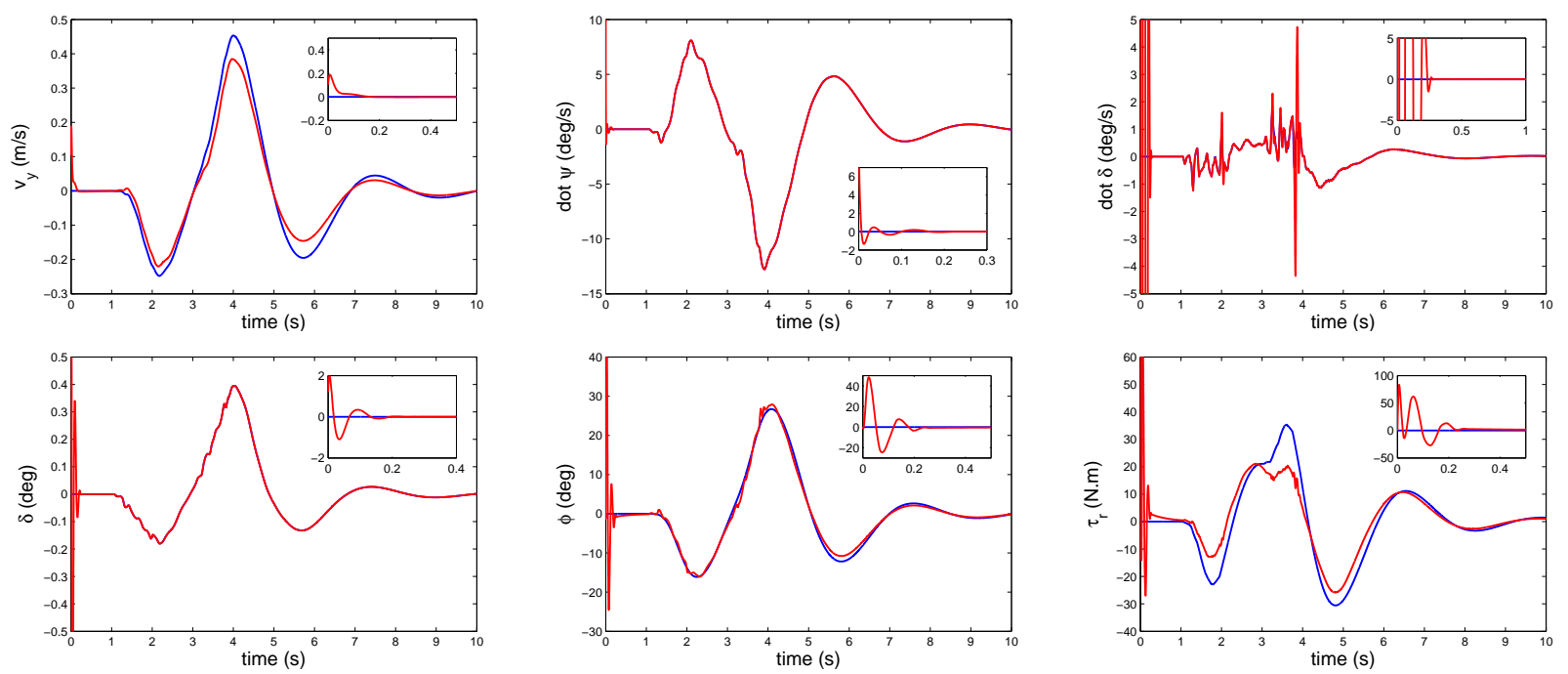

Fig. 8. Double lane change at $100 \mathrm{~km} / \mathrm{h}$. In blue, model results and in red, estimation result
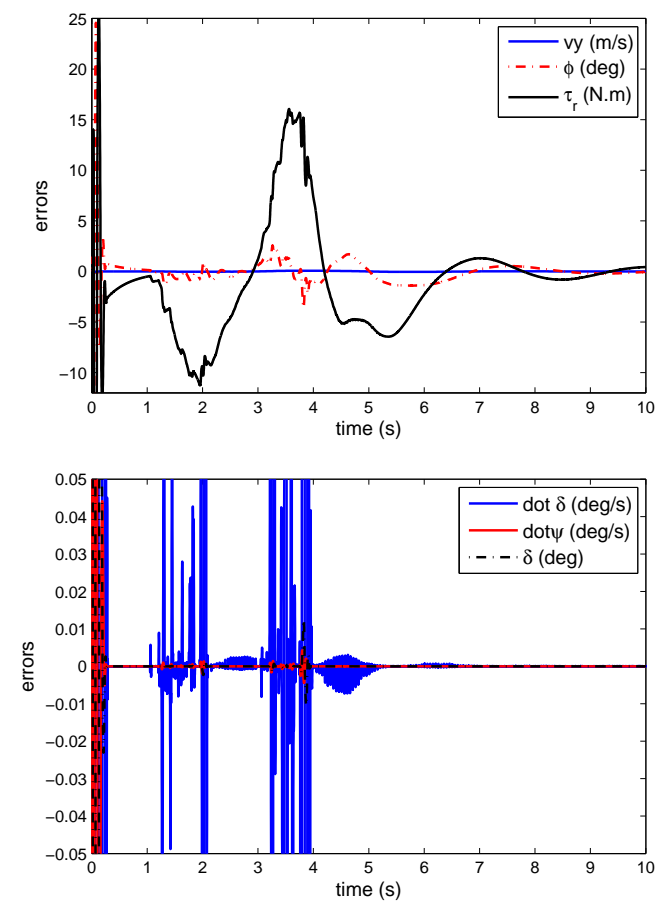

Fig. 9. Double lane change at $100 \mathrm{~km} / \mathrm{h}$. Estimation error

In the first scenario, we consider again the double lane change maneuver with forward speed at $100 \mathrm{~km} / \mathrm{h}$. In figure 8, some estimated states and the two unknown inputs are depicted. One can conclude that the observer provides satisfactory results. Since the total relative degree is equal to 3 , the yaw rate $(\dot{\psi})$, the steering rate $(\dot{\delta})$ and the steering angle $(\delta)$ are exactly estimated with finite-time convergence as shown by small zoom onside each sub-figure. The remaining states, namely the lateral speed $\left(v_{y}\right)$, the roll rate $(\dot{\varphi})$, the tire lateral forces $\left(F_{y f}, F_{y r}\right)$ and the two unknown inputs are estimated in finite-time with a bounded estimation error (figure 9). Moreover, it is possible to deal with the problem of transient phase by tuning the observer's parameters as discussed in [37].
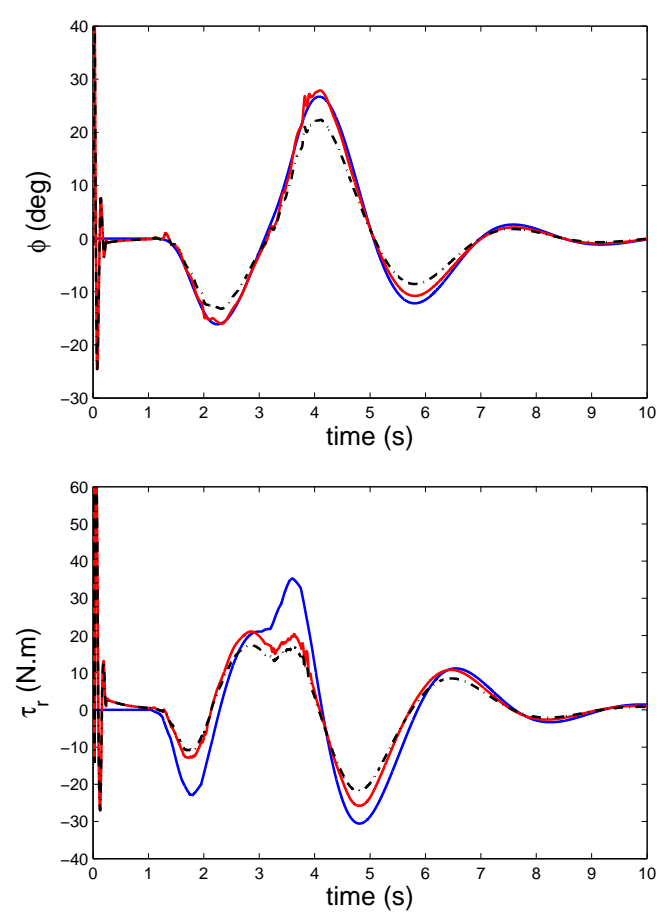

Fig. 10. Double lane change at $100 \mathrm{~km} / \mathrm{h}$. Robustness with respect to parameter variations ( $+20 \%$ variation on the nominal mass and inertia values). In blue, model results, in red estimation result by using nominal parameter and in black, estimation result by introducing uncertainty

In order to illustrate the performances of the proposed observer in the presence of modeling uncertainties, the observer is designed by using the linear motorcycle nominal model. In the nonlinear model, all bodies' mass and inertia are considered with a $20 \%$ variation with respect to their nominal values. As shown in figure 10, the observer ensures an acceptable estimations for almost the state variables and the unknown inputs. Once again, Three of eight states are exactly estimated despite uncertainty whereas, the remaining variable 

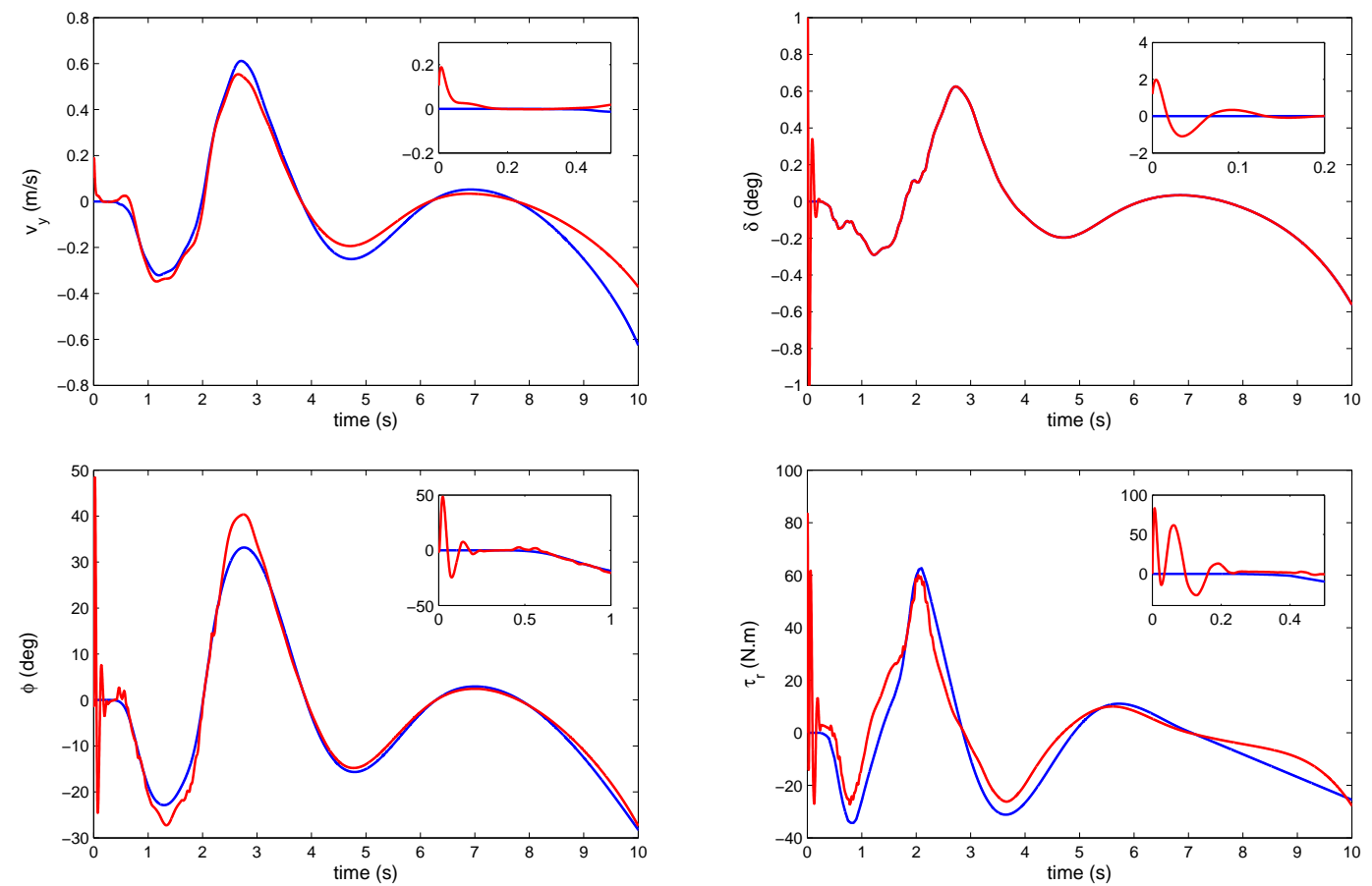

Fig. 11. Double lane change at $90 \mathrm{~km} / \mathrm{h}$. Robustness with respect to the forward speed $v_{x}$. In blue, model results and in red, estimation result


Fig. 12. Double lane change at $110 \mathrm{~km} / \mathrm{h}$. Robustness with respect to the forward speed $v_{x}$. In blue, model results and in red, estimation result 
are estimated in finite-time with an acceptable bounded estimation error.

As explained previously, the longitudinal velocity $v_{x}$ is considered constant, but in real situations, forward speed is also subject to variations. The observer is constructed by choosing a nominal value $v_{x}=100 \mathrm{~km} / \mathrm{h}$ but in the simulated system, a $10 \%$ variation with respect to the nominal value is assumed. Estimation results are depicted in figures 11 and 12 . For exact estimation, the steering angle $\delta$ estimation is given as an example where for bounded error estimation, the lateral speed estimation $v_{y}$ is shown. However, the estimations of the unknown inputs are visibly affected by the time varying longitudinal speed, in particular, at the maximum values.

\section{CONCLUSION}

The present paper deals with the problem of observer design for simultaneously estimating states and unknown inputs for a complex system such that a motorcycle vehicle. For that purpose, an Unknown Inputs High Order Sliding Mode observer is proposed and validated.

Three main contributions are detailed. The first one concerns the validation of the motorcycle nonlinear model with professional simulator data and thus, by considering two main scenarios: a double lane change at different forward speed and a cornering along a constant radius with forward speed variation. The second contribution concerns a full comparison between the nonlinear and the linear models for the same previous scenarios. Conclusion about the effect of the nonlinearities on the motorcycle driving behavior is discussed. Finally, the effectiveness of the observer is demonstrated on a nonlinear model and with a different initial conditions.

It is shown that, by introducing some rearrangement, the observability of a given model can be achieved, and the resulting model representation fulfill the detectability condition. Validation of the observer is proven despite the presence of parameter uncertainties and/or forward speed variation. It is shown that all measurable signals and their successive derivatives are exactly estimated with a finite-time convergence. This is guaranteed if the plant model can be transformed to the normal form by using a suitable transformation. The remaining states are estimated with a finite-time convergence and a bounded error estimation. Nevertheless, a wide variation of the forward speed can be seriously affect the observer performance. This issue constitute our future work.

\section{APPENDIX}

\begin{tabular}{|c|c|}
\hline motorcycle & \\
\hline$v_{x}, v_{y}:$ & longitudinal and lateral velocity \\
\hline$\varphi, \psi, \delta:$ & roll, yaw and steer rotations \\
\hline$\tau_{r}$ & rider torque \\
\hline$F_{y f}, F_{y r}:$ & lateral force \\
\hline$M:$ & motorcycle mass matrix \\
\hline$Q$ & $\begin{array}{l}\text { motorcycle generalized effort vec- } \\
\text { tor }\end{array}$ \\
\hline \multicolumn{2}{|l|}{ notations } \\
\hline$\dot{x}, \ddot{x}:$ & $\begin{array}{l}\text { derivatives of a variable } x \text { w.r.t } \\
\text { time }\end{array}$ \\
\hline$\hat{x}:$ & estimate of a variable $x$ \\
\hline$x^{T}:$ & transpose of vector or matrix $x$ \\
\hline$x_{f}, x_{r}$ & denotes front and rear \\
\hline \multicolumn{2}{|l|}{ motorcycle } \\
\hline$m_{G_{r}}, m_{G_{f}}, m_{G_{l}}, m_{G_{s}}$ & $165.13,9.99,7.25,8[\mathrm{~kg}]$ \\
\hline$m_{G_{B u}}, \quad m_{G_{B l}}, \quad m_{R_{f}}$, & $43.52,25.84,0,14.7[\mathrm{~kg}]$ \\
\hline $\begin{array}{l}m_{R_{r}} \\
x_{v G_{r}}, \quad x_{v G_{f}}, \quad x_{v G_{l}},\end{array}$ & $39,65.07,80.13,-25[\mathrm{~cm}]$ \\
\hline$x_{v G_{S}}$ & \\
\hline$x_{v G_{B u}}, x_{v G_{B l}}, x_{v R_{f}}$, & $-23.04,13.4,95,-42[\mathrm{~cm}]$ \\
\hline $\begin{array}{l}x_{v R_{r}} \\
z_{v G_{r}}, z_{v G_{f}}, z_{v G_{l}}, z_{v G_{S}}\end{array}$ & $53.2,104.34,60.27,34[\mathrm{~cm}]$ \\
\hline$z_{v G_{B u}}, \quad z_{v G_{B l}}, \quad z_{v R_{f}}$, & $80.01,50.4,29,29[\mathrm{~cm}]$ \\
\hline $\begin{array}{l}z_{v R_{r}} \\
x_{G_{f}}, x_{G_{l}}, x_{R_{f}}\end{array}$ & $10.2,6.04,6.9[\mathrm{~cm}]$ \\
\hline$z_{G_{f}}, z_{G_{l}}, z_{R_{f}}$ & $35.51,-10.88,-45.49[\mathrm{~cm}]$ \\
\hline$I_{x f}, I_{x l}, I_{x u b}, I_{x l b}$ & $1.341,0,0.9,0.5\left[\mathrm{Kg} / \mathrm{m}^{2}\right]$ \\
\hline$I_{z f}, I_{z l}, I_{z r}, I_{z u b}, I_{z l b}$ & $0.4125,0,14.982,0.9,0.5\left[\mathrm{Kg} / \mathrm{m}^{2}\right]$ \\
\hline$C_{x z r}, C_{x z u b}$ & $3.691,0.433\left[\mathrm{Kg} / \mathrm{m}^{2}\right]$ \\
\hline$i_{y r f}, i_{y r r}$ & $\begin{array}{l}\text { wheels spin inertia } 0.484,0.638 \\
{\left[\mathrm{~kg} \cdot \mathrm{m}^{2}\right]}\end{array}$ \\
\hline$\rho_{f}, \rho_{r}$ & wheels radius $29,29[\mathrm{~cm}]$ \\
\hline & tire trail $-4.89[\mathrm{~cm}]$ \\
\hline$F_{z f}$ & front tire normal force $1543.5[\mathrm{~N}]$ \\
\hline$\sigma_{f}, \sigma_{r}$ & tire's relaxation $[\mathrm{m}]$ \\
\hline$\epsilon$ & castor angle -0.4189 [rad] \\
\hline$C_{\delta}$ & $\begin{array}{l}\text { handlebar damping } \quad 12.6738 \\
{\left[\mathrm{~N} . \mathrm{m}^{-1} . \mathrm{s}\right]}\end{array}$ \\
\hline$g$ & gravity force $9.81[\mathrm{~N}]$ \\
\hline$C_{f 1}, C_{r 1}$ & $\begin{array}{l}\text { front and rear tire's sideslip stiff- } \\
\text { ness }-22408,-17657[\mathrm{~N} / \mathrm{rad}]\end{array}$ \\
\hline$C_{f 2}, C_{r 2}$ & $\begin{array}{l}\text { front and rear tire's camber stiff- } \\
\text { ness }-1056.3,-518.49[\mathrm{~N} / \mathrm{rad}]\end{array}$ \\
\hline
\end{tabular}

$\boldsymbol{E}=\left[\begin{array}{cccccccc}0 & b_{12} & 0 & 0 & 0 & 0 & 1 & 1 \\ 0 & b_{22} & b_{23} & b_{24} & 0 & 0 & x_{v R_{f}} & x_{v R_{r}} \\ 0 & b_{32} & 0 & b_{34} & b_{35} & b_{36} & 0 & 0 \\ 0 & b_{42} & b_{43} & C_{\delta} & b_{45} & b_{46} & \eta & 0 \\ 0 & 0 & 1 & 0 & 0 & 0 & 0 & 0 \\ 0 & 0 & 0 & 1 & 0 & 0 & 0 & 0 \\ b_{71} & b_{72} & 0 & b_{74} & b_{75} & b_{76} & -v_{x} & 0 \\ b_{81} & b_{82} & 0 & 0 & b_{85} & 0 & 0 & -v_{x}\end{array}\right]$

\section{REFERENCES}

[1] Amans, B. and Moutreuil, M., "RIDER Project . Research on accidents involving powered two-wheelers". Final Report $\mathrm{n}^{\circ}$ RIDER200503-10, French National Agency of Research, 2005.

[2] Evangelos Bekiaris, "SAFERIDER Project". Final Report n ${ }^{\circ}$ RIDER200503-10, French National Agency of Research, 2010.

[3] R.S. Sharp and D.J.N. Limebeer, "A Motorcycle Model for Stability and Control Analysis", Multibody System Dynamics, vol. 6, pp 123-142, 2001.

[4] V. Cossalter and R. Lot, "A motorcycle multibody model for real time simulation based on the natural coordinates approach", Vehicle System Dynamics, vol. 37(6), pp 423-447, 2002. 


\begin{tabular}{l} 
parameters $a_{i j}$ \\
$a_{11}=\sum m_{i}, a_{12}=\sum_{i} m_{i} x_{v i}, a_{13}=-\sum m_{i} z_{v i}, a_{14}=$ \\
$\sum_{j} m_{j} x_{j}, a_{22}=\sum_{i} m_{i} x_{v i}^{2}+\sin \epsilon^{2}\left(I_{x f}+I_{x l}\right)+\cos \epsilon^{2}\left(I_{z f}+\right.$ \\
$\left.I_{z l}\right)+2 I_{z r}+I_{z u b}+I_{z l b}, a_{23}=-\sum_{i} m_{i} x_{v i} z_{v i}-\left(I_{x f}+I_{x l}-\right.$ \\
$\left.I_{z f}-I_{z l}\right) \cos \epsilon \sin \epsilon+2 C_{x z r}+C_{x z u b}, a_{24}=\sum_{j} m_{j} x_{v j} x_{j}+$ \\
$\left(I_{z f}+I_{z l}\right) \cos \epsilon, a_{33}=\sum_{i} m_{i} z_{v i}^{2}+2 I_{x r}+I_{x l b}+I_{x u b}+$ \\
$\sin \epsilon^{2}\left(I_{z f}+I_{z l}\right)+\cos \epsilon^{2}\left(I_{x f}+I_{x l}\right), a_{34}=-\sum_{j} m_{j} z_{v j} x_{j}+$ \\
$\sin \epsilon\left(I_{z f}+I_{z l}\right), a_{44}=\sum_{j} m_{j} x_{j}^{2}+I_{z f}+I_{z l}$ \\
parameters $b_{i j}=-b_{x} \sum_{i} m_{i} x_{v i}, b_{23}=$ \\
$b_{12}=-\sum m_{i} v_{x}, b_{22}=-v_{y}=-v_{y}=$ \\
$-\left(i_{y r f} / \rho_{f}+i_{y r r} / \rho_{r}\right) v_{x}, b_{24}=-i_{y r f} / \rho_{f} \sin \epsilon v_{x}, b_{32}=$ \\
$\left(\sum_{i} m_{i} z_{v i}+i_{y r f} / \rho_{f}+i_{y r r} / \rho_{r}\right) v_{x}, b_{34}=i_{y r f} / \rho_{f} \cos \epsilon v_{x}$, \\
$b_{35}=\sum_{i} m_{i} z_{v i} g, b_{36}=-g \sum_{j} m_{j} x_{j}+F_{z f} \eta, b_{42}=$ \\
$-\left(\sum_{j} m_{j} x_{j}-i_{y r f} / \rho_{f} \sin \epsilon\right) v_{x}, b_{43}=-i_{y r f} / \rho_{f} \cos \epsilon v_{x}$, \\
$b_{45}=F_{z} \eta-g \sum_{j} m_{j} x_{j}, b_{46}=F_{z} \sin \epsilon \eta-g \sin \epsilon \sum_{j} m_{j} x_{j}$, \\
$b_{71}=C_{f 1}, b_{72}=C_{f 1} x_{v R_{f}}, b_{74}=C_{f 1} \eta, b_{75}=C_{f 2} v_{x}$, \\
$b_{76}=v_{x}\left(-C_{f 1} \cos \epsilon+C_{f 2} \sin \epsilon\right), b_{81}=C_{r 1}, b_{82}=$ \\
$C_{r 1} x_{v R_{1}}, b_{74}=C_{f 1} \eta, b_{75}=C_{r 2} v_{x}$ \\
$i=G_{r}, G_{f}, G_{l}, G_{s}, G_{R_{f}}, G_{R_{r}}, G_{B_{l}}, G_{B_{u}}$ \\
$j=G_{f}, G_{l}, G_{R_{f}}$ \\
\hline
\end{tabular}

[5] S. Hima, L. Nehaoua, N. Seguy and H. Arioui, "Suitable Two Wheeled Vehicle Dynamics Synthesis for Interactive Motorcycle Simulator", In Proc. of the IFAC World Congress, pp 96-101, Seoul, Korea, July 6-11, 2008.

[6] L. Nehaoua, L. Nouvelière and S. Mammar, "Dynamics modeling of a Two-wheeled vehicle using Jourdain's principle", In Proc. of the Mediterranean Conference on Control \& Automation , pp 1088-1093, Corfu, Greece, 2011.

[7] R. Lot, S. Rota; M. Fontana and V. Huth, "Intersection Support System for Powered Two-Wheeled Vehicles: Threat Assessment Based on a Receding Horizon Approach", IEEE Trans. Intel. Transp. Sys., 2012, Vol. 13(2), pp. 805-816.

[8] S. Bobbo and V. Cossalter and M. Massaro and M. Peretto, "Application of the "Optimal Maneuver Method' for Enhancing Racing Motorcycle Performance". SAE International Journal of Passenger Cars - Mechanical Systems, pp. 1311-1318, 2009.

[9] H. Slimi and H. Arioui and S. Mammar, "Motorcycle Speed Profile in Cornering Situation". American Control Conference (ACC'10), Baltimore, Maryland, USA, pp. 1172-1177, 2010.

[10] S. Evangelou, "Influence of Road Camber on Motorcycle Stability". Journal of Applied Mechanics, Vol. 75, issue 6, pp. 231236, 2008

[11] R. Rajamani, D. Piyabongkarn, V. Tsourapas, and J.Y. Lew, "Parameter and State Estimation in Vehicle Roll Dynamics", IEEE Trans. Intel. Transp. Sys., 2011, Vol. 12(4), pp. 15581567

[12] B.A.M. van Daal, "Design and automatic tuning of a motorcycle state estimator". Master thesis, TNO Science \& Industry, Eindhoven University of Technology, Eindhoven, Nederland, 2009.

[13] Ichalal, D. and Arioui, H. and Mammar, S., "Observer design for two-wheeled vehicle: A Takagi-Sugeno approach with unmeasurable premise variables". 19th Mediterranean Conference on Control \& Automation (MED'11), Corfu, Greece, 2011.

[14] I. Boniolo, M. Tanelli, S.M. Savaresi, "Roll Angle Estimation in Two-Wheeled Vehicles". 17th IEEE International Conference on Control Applications (part of 2008 IEEE Multi-conference on Systems and Control), San Antonio, TX, pp. 31-36, 2008.

[15] I. Boniolo, M. Tanelli, S.M. Savaresi, "Roll angle estimation in two-wheeled vehicles". IET Control Theory \& Applications, Vol.3, n.1, pp.20-32, 2009.

[16] Boniolo, I. and Savaresi, SM, "Estimate of the Lean Angle of Motorcycles", ISBN 978-3-639-26328-2, VDM Verlag, Germany, 2010.

[17] Teerhuis, AP. and Jansen, STH., "Motorcycle state estimation for lateral dynamics", Bicycle and Motorcycle Dynamics, 2010.

[18] Lot R., Cossalter V., Massaro M. "Real-Time Roll Angle Estimation for Two-Wheeled Vehicles", Proc. of the ASME 2012 Conference on Engineering Systems Design And Analysis, Nantes, France

[19] De Filippi, P. and Corno, M. and Tanelli, M. and Savaresi, S., "Single-Sensor Control Strategies for Semi-active Steering
Damper Control in Two-Wheeled Vehicles", IEEE Transactions on Vehicular Technology, 61(2), pp. 813-820, 2011.

[20] Gasbarro L., Beghi A., Frezza R., Nori F., Spagnol C., "Motorcycle trajectory reconstruction by integration of vision and MEMS accelerometers" Proc. of the 43th IEEE Conference on Decision and Control, pp. 779Ú 783, 2004

[21] Schlipsing, M., Schepanek, J., Salmen, J., "Video-based roll angle estimation for two-wheeled vehicles", Proc. of the IEEE Intelligent Vehicles Symposium, pp. 876-881, 2011.

[22] D. Ichalal, H. Arioui, and S. Mammar. "Observer design for two-wheeled vehicle: A takagi-sugeno approach with unmeasurable premise variables". In 19th Mediterranean Conference on Control \& Automation (MED'11), Corfu, Greece, June 20-23 2011.

[23] D. Ichalal, H. Arioui, and S. Mammar. "Estimation de la dynamique latérale pour véhicules à deux roues motorisés". In 7th Conférence Internationale Francophone d'Automatique (CIFA'2012), Grenoble, France, July 1-6 2012.

[24] L. Fridman, A. Levant and J. Davila, "Observation of linear systems with unknown inputs via high-order sliding-modes ". Int. J. of Systems Science, Vol. 38(10), 773-791, 2007.

[25] L. Nehaoua, M. Djemai and P. Pudlo "Virtual Prototyping of an Electric Power Steering Simulator", IEEE Transactions on Intelligent Transportation Systems, Vol. 14(1), 274-283, 2013

[26] L. Nehaoua, H. Arioui and S. Mammar "Motorcycle Riding Simulator: How to Estimate Robustly the Rider's Action?", IEEE Transactions on Vehicular Technology, Vol. 62(1), 80-88, 2013

[27] L. Fridman, A. Levant and J. Davila, "Observation and Identification Via High-Order Sliding Modes". Modern Sliding Mode Control Theory, Lecture Notes in Control and Information Science, Springer, Berlin, 2008.

[28] J. Davila, L. Fridman and A. Levant, "Second-order slidingmode observer for mechanical systems", IEEE Trans. on Automatic Control, Vol. 50, pp. 1785-1789, 2005.

[29] A. Levant, "Higher-order sliding modes, differentiation and output-feedback control". Int. J. of Control, Vol. 76, 924-941, 2003.

[30] L. Fridman, J. Davila and A. Levant, "Higher-order sliding modes observation for linear systems with unknown inputs". Nonlinear Analysis: Hybrid Systems, Vol. 5, pp. 189-205, 2011.

[31] H. Slimi, H. Arioui, L. Nouveliere and S. Mammar, "Advanced Motorcycle-Infrastructure-Driver Roll Angle Profile for Loss Control Prevention", 12th International IEEE Conference on Intelligent Transportation Systems., St. Louis, Missouri, U.S.A., October 3-7, 2009

[32] R.S. Sharp, "The stability and control of motorcycles", J.of Mechanical Engineering Science, Vol. 13, 316-329, 1971.

[33] G. Rill, "Simulation von Kraft-fahrzeugen", Vieweg, Braunschweig, Germany, 1994

[34] H.L. Trentelman, A.A. Stoorvogel, M. Hautus, Control Theory for Linear Systems, Springer-Verlag, London, Great Britain, 2001.

[35] A. Isidori, "Nonlinear Control Systems", London: SpringerVerlag, 1996.

[36] M. Mueller, "Normal form for linear systems with respect to its vector relative degree". Linear Algebra and its Applications, Vol. 430, 1292-1312, 2009.

[37] A. Levant,A. Michael. " Adjustment of High-Order SlidingModes ", Int.Journal of Robust and Nonlinear Control, 19(15), pp. $1657-1672,2009$ 